\title{
Debreu's apologies for mathematical economics after 1983
}

\author{
TILL DÜPPE \\ University of Hamburg
}

\begin{abstract}
When reassessing the role of Debreu's axiomatic method in economics, one has to explain both its success and unpopularity; one has to explain the "bright shadow" Debreu cast on the discipline: sheltering, threatening, and difficult to pin down. Debreu himself did not expect to have such an influence. Before he received the Bank of Sweden Prize in 1983 he had never openly engaged with the methodology or politics of mathematical economics. When in several speeches he later rigorously distinguished mathematical form from economic content and claimed this as the virtue of mathematical economics, he did both: he defended mathematical reasoning against the theoretical innovations since the 1970s and expressed remorse for having promised too much because it cannot support claims about economic content. The analysis of this twofold role of Debreu's axiomatic method raises issues of the social and political responsibility of economists over and above standard epistemic issues.
\end{abstract}

Keywords: Gerard Debreu, axiomatic method, theoretical practice, ideology, social responsibility

JEL Classification: A11, B31, B41, C02

\section{THE INVISIBLE HAND OF FORMALISM}

Gerard Debreu cast a "bright shadow" on the discipline of economics. He is known to all who had to learn his proof of the existence of a competitive equilibrium at graduate school, crowned with the Bank of Sweden Prize, yet cursed by all economists who want to say more than $x \in X$. Although economists are trained in Debreu's proof, they neither read the 1954 article nor his book of 1959, Theory of value (noteworthy as the last 'theory of value' in economics until today). Even if he is 
now peremptorily rejected or belittled as outmoded, contemporary economists have profited from Debreu since he advanced the belief in, and fostered the reputation of, economics as an incontestable science. Economics today can be sold for a higher price than before Debreu, yet current theoretical battles seem less heated than in the days of, for example, the socialist calculation debate. Furthermore, although the entire effort of Debreu was motivated by, and becomes intelligible only by reference to, his training in a specific school in mathematics"Bourbaki"-there are but a few economists who have ever heard of that name, and even less who have read it. Debreu did, meticulously, and everything he said about his own work, as we will see, can be found almost word for word in Bourbaki. ${ }^{1}$

This elusive influence of Debreu is apparent in the way others have assessed his work. "Although there had been quantum leaps of mathematical sophistication before in the history of economics, there had never been anything like this", Roy Weintraub commented (2002, 114). Werner Hildenbrand called his work "scientific contributions in the most honest way possible", and Paul Samuelson "an unpretentious nononsense approach" (quoted in Weintraub 2002, 113). Oliver Williamson, the ambitious new-institutionalist and Debreu's colleague at Berkeley, said he "always marveled at Gerard's quiet, kind and inclusive ways-an example being his insistence on referring to me as an 'economic theorist', my protests to the contrary notwithstanding" (quoted in Anderson 2005, 4). Debreu was right to insist, and indeed, as Varian wrote after the Bank of Sweden Prize, "not only have Debreu's works contributed to mathematical economics; they have contributed to the science of economics as a whole" (Varian 1984, 4).

Debreu's elusive influence is also apparent in the way others have discussed his work. Weintraub, who has given us the most complete image of Debreu up to now, employs a distinction from the historian of mathematics Leo Corry, between the "body" and the "image" of mathematics (Weintraub 2002; Corry 1992, 1997). From the point of view of today Debreu's influence on the body of economics could be

\footnotetext{
1 'Nicolas Bourbaki' is the pseudonym for a collective of mathematicians founded in 1935 at the École Normale Supérieure in Paris. Debreu was taught by its oldest member, Henri Cartan, and kept in close contact with André Weil in Chicago. In a nutshell, Bourbaki's work amounts to a turn inward, a mathematization of mathematics, and thus a separation from sciences such as physics, so that Weintraub rightly speaks of an oxymoron in 'applying Bourbaki' to economics (2002, 103). One aim of this paper is to show how this oxymoron was so productive in spite of Debreu's rigor in keeping up that separation.
} 
called zero, in that general equilibrium theory (GET) is the economics of yesterday. While GET had mirrored most analytic advances in economic theory before Debreu, after Debreu most theoretical innovations came as alternatives to GET (from game theory to complexity theory). In this search for alternatives, Debreu became the bogeyman man of both orthodox and heterodox economists deploring how unrealistic and irrelevant economic theory had become. Regarding the image of economics, however, it is easy to underestimate Debreu's influence on the method, style, institutions, intellectual culture, and professional ethos of economists. Did Debreu, in whatever murky fashion, not contribute to the immense growth and increased social status of the economics profession and its epistemic dominance in wider economic discourse? In short, concerning the body of economics, Debreu's influence can be easily belittled, but concerning the image easily undervalued. The broader the view taken, the greater yet subtler his influence appears.

At the Nobel festivities in 1983, after the King had handed over the prize, Debreu himself reflected on this puzzling influence in the few words he had chosen for his banquet speech. In order to explain his role in economics, he used the metaphor of the invisible hand.

[A] scientist knows that his motivations are often weakly related to the distant consequences of his work. The logical rigor, the generality, and the simplicity of his theories satisfy deep personal intellectual needs, and he frequently seeks them for their own sake. But here, as in Adam Smith's famous sentence, he seems to be 'led by an invisible hand to promote an end which was not part of his intention', for his personal intellectual fulfillment contributes to promoting the social interest of the scientific community. [...] It was my great fortune to begin my career at a time when economic theory was entering a phase of intensive mathematization and when, as a result, the strength of that invisible hand had become irresistible (Debreu 1984a).

Debreu's use of the metaphor of the invisible hand has subtle connotations. By using this metaphor, Debreu, first, admitted that the primary concern of his intellectual life was not the "social interest of the scientific community"-whatever that might be. Instead, he was engaged in mathematical economics for its own sake. Like the baker in Smith's market, the mathematical economist pursues rigor only for his own interest-for the intrinsic appeal and deep satisfaction of the 
mathematical experience-yet mysteriously, 'led by an invisible hand', this turns out to promote the social interest of the discipline. Debreu thereby responds to a common critique of economics, that mathematics has become an end in itself, is overused excessively, and leads economics to the edge of irrelevance, in the same way that clergymen's complaints about the use of money were once rebutted by economists with the invisible hand.

Using this metaphor, Debreu thus acknowledged that there is a separation between the intellectual motivations of mathematical economists and the consequences for economics. "Logical rigor, generality and simplicity" are thus not virtues that stem from an interest in economics itself. Nothing in economics-whatever that might be-motivated his use of mathematics, whether the epistemic issues (the complexity of the economy), ontological matters (prices are numerical things), or semantic reasons (the suitability of mathematics as the language of economics) focused on by mainstream philosophy of science. Mathematical reasoning and the treatment of economic content are rigorously separated, which is the tenet of Debreu's axiomatic method. Debreu was unique among economists in actually defending this separation methodologically. That reflects his Bourbakist background and makes him, and his neo-Walrasian community, the only true formalists in economics.

With the metaphor of the invisible hand, moreover, Debreu acknowledged the "irresistible" influence his axiomatic method had had. Since his intervention, the economics profession has moved ever further away from being able to connect to a pre-Debreuvian way of intellectual life. Whatever their intellectual motivation, economists inevitably end up reinforcing the current state, as if one engages in economics only for the sake of the mathematical value of rigor. Debreu's remarks can also be seen as acknowledging this tragic aspect of the influence of mathematical economics: that attempts to provide a theoretical alternative only reinforce the status quo of the profession.

With the metaphor of the invisible hand, Debreu admitted that his influence had gone far beyond his own intentions when entering the Cowles Commission in 1949. Debreu was surprised by his success, and admitted that he had never considered the possible unintended consequences of mathematical virtues in economics. Indeed, during his active intellectual life up to 1983 he never felt the need to openly defend the methodology of his work, let alone participate in debates on 
mathematics in economics exactly because he assumed their separation. With the Bank of Sweden Prize, however, coming after he had already largely withdrawn from active research, he had to recognize that his influence had gone far beyond the separation he assumed. Hence, I interpret the use of this metaphor as an "apology" not only in the sense of a defensive 'apologia' of mathematical economics, but also as a way of saying sorry for having caused a misunderstanding about the nature of mathematical economics. Even if Debreu would not admit this feeling to himself, insisting on the axiomatic separation of mathematical form and economic content was a way of saying: sorry, dear economist, mathematical reasoning does not suffice for economics.

With the metaphor of the invisible hand, Debreu effectively, did both: he defended the importance of mathematical economics because of its beneficial results for the profession beyond the GET he applied it to; and he apologized for it, admitting its insufficiency for any economic theory. With his defense, he acknowledged the pervasiveness of mathematics in post-Walrasian economics, while with his remorse he acknowledged its irrelevance. It was in this sense that Debreu cast a 'bright shadow' on post-war economics. It is not trivial to know whether one stands under his sheltering and threatening influence or not. What Debreu acknowledged was an invisible hand of formalism that accounts for the success and unpopularity of mathematical economics since the 1950s.

What follows is an attempt to trace this invisible hand of formalism in Debreu's methodological speeches after 1983. The core of Debreu's methodology is the axiomatic separation of meaning and structure, or as he translates, the separation of economic content and mathematical form, or as he also says, the separation of interpretation and theory. In Debreu's words, "Allegiance to rigor dictates the axiomatic form of the analysis where the theory, in the strict sense, is logically entirely disconnected from its interpretations" (1959, x).

The two questions to which Debreu's speeches reply, are first what is the axiomatic method (section two)?, and second what is its value for the economist (section three)? The exposition of his methodology will show that the separation of meaning and structure frustrates any conception of a theoretical practice and thus any actual role for the economist. The self-limiting character of mathematical economics, 
which has often been noted, ${ }^{2}$ implies the redundancy of the theoretical practices of abstracting, simplifying, explaining, isolating, or any other kind of reasoning upon a particular epistemic interest commonly discussed in mainstream philosophy of science. These terms are-as I show in section two-unsuitable for tracing the influence of the axiomatic method on the discipline, for Debreu pursued mathematical rigor for its own sake.

As a consequence, when defending the advantages of the axiomatic method, Debreu must continuously back away from his separation of mathematical form and economic content-as shown in section three. Its benefits for the economist can only be justified by smuggling other intellectual values than axiomatic rigor back into economic theory. In other words, only as long as there is no separation of theory and interpretation, can economic theory be relevant for the economist. This negative result leaves open the question about how the impact of the axiomatic method can be traced. In this respect, issues of social and political responsibility, rather than ontological or epistemological concerns, emerge from the discussion. The axiomatic discreetness of mathematical economists allows others to use their authority without their involvement. This, in turn, is the very reason why Debreu, after 1983, saw the need for setting his methodology right in the first placesaying sorry for not preventing unintended uses of his work.

\section{THE SCHEME OF THE AXIOMATIC METHOD AND ITS FIFTH WHEEL: INTERPRETATION}

At three prominent places Debreu had the occasion to speak out about his method: in his Nobel lecture (1984b), in his Frisch Memorial lecture (1986), and in his presidential address at the AEA (1991). These speeches strongly resemble each other and closely echo Bourbaki's methodological writings $(1949,1950)$. In one repeated formulation Debreu describes the 'scheme' of the axiomatic method (1984b, 275; 1986, 1256-1258; 1991, 4-5). This scheme follows step-by-step what Bourbaki had said about the concept of a mathematical structure.

It now can be made clear what is to be understood, in general, by a mathematical structure. The common character of the different concepts designated by this generic name, is that they can be

\footnotetext{
${ }^{2}$ Regarding the axiomatic method see, e.g., Clower 1995; regarding GET, e.g., Kirman 1989; regarding structuralism, e.g., Hands 1985; and regarding the history of economic theory, e.g., Blaug 2003.
} 
applied to sets of elements whose nature has not been specified; to define a structure, one takes as given one or several relations, which these elements enter [...]; then one postulates that the given relation, or relations, satisfy certain conditions (which are explicitly stated and which are the axioms of the structure under consideration). To set up the axiomatic theory of a given structure, amounts to the deduction of the logical consequences of the axioms of the structure (Bourbaki 1950, 225-226; emphasis added).

The only objects of mathematics according to Bourbaki are structures, since only structures, not the meaning of the elements, can be the playground of mathematical rigor. In Debreu this appears as follows:

An axiomatized theory first selects its primitive concepts and represents each one of them by a mathematical object. [...] Next assumptions on the objects representing the primitive concepts are specified, and consequences are mathematically derived from them. The economic interpretation of the theorems obtained is the last step of the analysis. According to this schema an axiomatized theory has a mathematical form that is completely separated from its economic content (Debreu 1986, 1265).

In order to axiomatize a theory, one is to follow a scheme consisting of five steps: selecting, representing, specifying, deriving, and interpreting.

\section{Selecting primitive concepts}

The subject of the sentence, "an axiomatized theory selects its primitive concepts", is apparently ill-expressed, yet, I suggest, symptomatic of Debreu's methodology. An axiomatized theory does not "do" anything. Debreu does. He axiomatizes GET. He makes the first selection. And this selection is crucial for the assessment of the entire effort in that it presumably expresses his theoretical interest-including, for example, the purpose for which a theory is developed, the intellectual space in which one operates, and the limits of the entire enterprise. An axiomatic analysis is an analysis of a theory that is already in place, and that limits the axiomatic discourse. So, is it possible to assess Debreu's selection of primitive concepts in terms of his commitment to a particular theoretical interest?

At this point, Debreu's alleged "Walrasianism" must be addressed. The received understanding of Debreu is that he shared a theoretical 
interest with Walras and transformed it into what came to be called neoWalrasian economics. In this account, Walras formulated the theory ("the economy" as a system of $n$ equations), but missed the rigorous proof ( $n$-equations with $n$ - 1 unknowns, thus solvable) which Debreu delivered 80 years later (using a rigorous topological theorem). So, does Debreu share a theoretical interest with Walras?

It was and remains open to debate what exactly Walras's theoretical interest was (see, e.g., Walker 1983; 2006). When comparing Walras's enduring interest in pursuing a scientific social science with Debreu's motivations, one certainly must point to Walras's belief in the wellordered reality of the economy. When attacked for the descriptive inaccurateness of his mathematical model-the measurability of utility figured prominently-he insisted that his model was an immediate expression of the market system (see his letter to Garnier, in Ingrao and Israel 1990, 147). Walras associated his system of equations with 'the economy' on the basis of a metaphysical belief that the economy is capable and worthy of possessing mathematical truth. That is, economic reality can be expressed, rather than merely represented, with the beauty, consistency, and simplicity of mathematics. At the heart of Walras's mathematical economics was not the belief that the analogy of Newtonian mechanics and market forces actually holds in reality, as he officially framed his theory. Rather, the mathematical expression of the economy shows that the economy is worth its reality! Walras was moved by a Platonistic belief that the meaning of the structure of mathematics was the same as the meaning of the structure of "the economy."

Debreu, in contrast, had no expressive interest in any aspect of the reality of the economy when axiomatizing GET. "In proving existence one is not trying to make a statement about the real world, one is trying to evaluate the model" (Debreu, in Feiwel 1987, 243). In Weintraub's words: "The objective was no longer to represent the economy, whatever that might mean, but rather to codify the very essence of that elusive entity, the Walrasian system" (Weintraub 2002, 121). In making Walras's theory itself the object of scrutiny, but neglecting Walras's theoretical interest, Debreu cut the tie with Walras. Blaug rightly calls this readaptation of Walras one of the "most remarkable Gestalt-switches in the interpretation of a major economic theory in the entire history of economic thought" (Blaug 2003, 150). Debreu and Walras did not share a theoretical interest. Rather, Debreu used Walras as a jumping off board 
for an enterprise that was quite differently motivated. Walras in Debreu is a placeholder for economic theory.

What Debreu did actually select was not a market theory at all, but 'primitive concepts', first of all 'commodity'. Did Debreu make a real choice by doing so? What did he rule out? Commodities are indeed the objects of markets: they are the things referred to in market theory because they are the things of value. The concept of commodities, and the question of how they 'have' value, was one locus of the preceding centuries' contest between theories of value (Jorland 2000). But Debreu's Theory of value does not even pose that question. Debreu did not select a particular meaning of 'commodity': his primitive concepts remain undefined, and undetermined. To choose 'commodity' as a primitive concept is to choose it as a concept of all possible market theories.

As Kant said that truth is a matter of statements, Debreu said that markets are a matter of commodities. With the word 'commodity' Debreu only points to a possible theoretical interest but does not address it. Even when Debreu introduces 'commodity' in chapter two of his Theory of value heuristically as something that is completely determined in physical terms regarding place, time, quantity, and quality, he does not select a particular meaning, but simply makes the concept appear to be capable of concreteness, and thus of interest for the economist. And so Debreu concludes this chapter with definitions in set-theoretical terms and adds: "All that precedes this statement is irrelevant for the logical development of the theory. Its aim is to provide possible interpretations of the latter" (1959, 35). Possible interpretations, not actual! The word commodity is for the economist like the carrot suspended in front of the donkey's eyes that it can never reach.

If there was any real choice, hidden behind Walras and the seemingly unproblematic concept of commodity, it was that economic theory has a structural character in the first place-as opposed, for example, to a conceptual, narrative, literary, or instructive character. If such was his choice, what theoretical interest does Debreu really share with other economic theorists? Can one say that Debreu does not need to be interested in the meaning of commodities in the same sense as Smith's baker does not need to be interested in moral codes but merely in his own interest? Is the meaning and structure of economic theory separated in the same sense as the constitution of commodities in markets is separated from the constitution of the value of goods? Do 
the formalism of market theories (the use of formal language) and the formalism in market theories (no substantive requirements) have the same roots?

Debreu, certainly, did not choose for structuralism in that sense. The analogy of the separation of meaning and structure in and of economic theory never occurred to him. For Debreu, 'structure' was a feature of market theories, not of the market: he does not discuss in what sense 'the economy' could be perceived as a 'structure' in the first place. Yet without perceiving himself as a 'structuralist', Debreu nevertheless instantiates the belief that the problem of economic theory is a matter of dealing with structures. And this is as true today as it was 50 years ago when the question of an economic theory of value disappeared in the structuralist verve of Theory of value.

\section{Representing primitive concepts as mathematical objects}

Whatever Debreu selected as a primitive concept, the choice is diluted when this concept is represented by something else-a mathematical object: $x$. Hence, the first two steps should be read within one breath: selecting-and-representing. Primitive concepts are not objects of selection, but appear already subjected to a representation, a displacement. Their meaning, let alone their reference, does not find its way into the formal analysis.

The notion of representation nevertheless suggests a common feature or similarity between the represented and what represents. Is there anything by virtue of which a mathematical object can represent a primitive concept? No. The very question of the conditions of representing cannot be posed in Debreu's scheme. Instead of representation, Debreu speaks more accurately of the substitution of primitive concepts by mathematical objects. These substituted concepts are not representations, but function as the identifiers of the mathematical objects-their nicknames. Representing primitive concepts as mathematical objects is thus an act of tagging the mathematical objects. This is to say it is not an act of abstraction, idealization, comparison, simplification, inference, deduction, induction, nor an act of abduction into another context (as Khan interprets the first two steps as a choice of metaphor). ${ }^{3}$

\footnotetext{
3 See Khan 1993. The difference between Bourbakian mathematical objects and metaphors is vital for understanding the role of mathematics in economics. Metaphors need to be interpreted. Mathematical objects could be interpreted.
} 
The primitive concept 'commodity' is thus represented as a mathematical object, an "element" in the "commodity space" $x \in X$. The remaining primitive concepts are not selected, so their meaning is not even substituted. For the structure of GET to be settled, two different relations need to be defined on the commodity space, namely 'preferences', and 'prices'. Defined by the commodity space, they are irrelevant to the question of a theory of economic value, but are rather the structural requirements for formulating the mathematical problem of consistency, the 'equilibrium'.

The consumption of a consumer, his set of possible consumptions, and his preferences are represented respectively by a point in the commodity space, a subset of the commodity space, and a binary relation in that subset (Debreu 1986, 1265).

Thus Debreu's "universe of discourse" consisting of 'commodities', 'consumers', and 'prices' is, as he requires, "explicitly listed at the outset" $(1959,3)$. In such terms Debreu described what is elsewhere called 'consumer choice'. How the binary relations with the nickname 'preferences' are related to the choices we make, as their reflections or their determinants, or any other queries we may have about choosing commodities, cannot even be asked. ${ }^{4}$

Again, one can speculate about the consequences on the broader context of economic discourse. Was not the question of price determination originally about how prices represent or express our acts of valuation, not the consistency of economic theory? Only then can all the fuss made about GDP, economic performance, growth and wealth mean something. If the consistency of economic theory can be formulated independently of this question, what then does Debreu show of the very idea of prices representing values? Did Debreu indirectly show something about the market if its theory is independent of its meaning? Did Debreu liberate the economist from the burden of interpreting in the same sense as the economic agent in markets is liberated from the social articulation of value?

\section{Specifying assumptions}

The next step is to specify 'assumptions'. As students learn in their MasColell, et al. course, the commodity space representing 'commodities' must be i) finite, ii) convex, and iii) have a lower bound; the binary

\footnotetext{
${ }^{4}$ See, for this distinction between reflection and determinant, Sen 1973.
} 
relations representing 'preferences' must be $j$ ) continuous, jj) strictly monotonously increasing, and jjj) strictly quasi-concave; and the technology space must be $k$ ) strictly convex. In a textbook from $1958 j$ )$k$ ) are listed for the first time as follows: no increasing returns to scale (producing more does not reduce average costs), at least one factor of production (things are not like 'air'), consumer wants cannot be saturated (we are all excessive if we can be) (see Weintraub 2002, 188).

After the first two steps, these two textbook specifications of assumptions must be two different things. The confusion is that between 'assumption' and 'axiom'. Assumptions are not specified on primitive concepts, let alone their referential meaning, but on the mathematical objects that substitute for these primitive concepts. To speak about 'assumptions' is misleading in the sense that Debreu does not assume something to be the case which, as with hypotheses, suppositions, or basic beliefs, could be at stake when theorizing. What Debreu calls 'assumptions' are, rather than epistemic priors, the result of the axiomatization-the axioms: "one postulates that the given relation, or relations, satisfy certain conditions (which are explicitly stated and which are the axioms of the structure under consideration)" (Bourbaki 1950, 226, emphasis added).

Debreu's axiomatization results in axioms stating the mathematical conditions of a consistent structure. Debreu, in other words, did not theorize in the face of the world, but in the face of a structure. As Anderson commented on his attitude to assumptions: "[Debreu] refused to comment on the reasonableness of assumptions, believing that his job was to make the assumptions clear, and it was the reader's job to assess them" (Anderson 2005, 6). It is sheer irony how in the neoWalrasian community such cautious treatment of economic assumptions could be taken up, as here in Egbert Dierker's survey of neo-Walrasian economics: "Economic knowledge is not required, but especially a reader without economic background will gain much by reading Debreu's classic 'Theory of Value'” (Dierker 1974, iii).

Accordingly, the task of the neo-Walrasian research program was to show the weakest conditions of an equilibrium-'weak' in terms of the Bourbakian hierarchy of mathematical structures, the weakest of all assumptions being $x \in X$. One great result arrived at, for example, was Andreu Mas-Colell's (1974) "An equilibrium existence theorem without complete or transitive preferences"; and, as an early work by David 
Schmeidler (1969) asked, are "Competitive equilibria in markets with a continuum of traders and incomplete preferences" possible?

Nevertheless, some of Debreu's axioms could have an economic interpretation. One economist even held that "the behavior of market economies depends on how convex the world is" (Kay, quoted in Ramrattan and Szenberg 2005, 6). While most other economists may have difficulties in imagining what a 'convex world' would look like, axioms like transitivity are indeed commonly understood as demanding something of the actual holding of preferences. Here the interpretive labor of the economics instructors begins. They literally invent narratives for mathematical objects, producing the impression of actual reference. If teachers emphasize intelligibility and keep the mathematics low, they ironically reinforce the mathematical bulwark against critical reflection. The same applies to those economists who took the undergraduate narratives literally as descriptive truths and went into behavioral economics. Most of this research confuses assumptions and axioms and actually reinforces the underlying structure that is independent of any interpretation. It was mostly by virtue of these 'secondary' interpretations of axioms that the neo-Walrasian community could achieve their success in producing a benchmark of economic theory. Axioms of choice such as independence and transitivity did not express the basic beliefs of the neo-Walrasian research program. There were none.

Again, one can speculate further on the more indirect effects of this confusion on the discursive environment of economics. If the mathematical weakness of axioms is confused with the philosophical weakness of assumptions this error may be transplanted into the political arena with very different connotations, namely with regard to freedom. Weak assumptions then amount to weak demands for particular behavior from economic agents, i.e., negative freedom. As Debreu only spoke about structures, other economists are relieved from having to consider whether economic agents should have a preference for particular goods. The $x$ of Debreu and the whatever you want of the liberals-is it the same? Do weaker assumptions make for a freer society?

Ruccio and Amariglio went further with this association of Debreu's rigor with liberal politics by arguing that the absence of the "body" of economic agents allows for new "re-evaluations of the experiences and distributions of pleasure and pain, work and desire, base and refined 
instincts, emotions and reasons, passions and interests, sex, race, and class" (2003, 101). Ruccio and Amariglio thus turn the complaints about the insignificance of Debreu's work on its head: precisely because there is no reference to bodily agents, Debreu, and neoclassical economics in general, frees agents for a post-modern play of meaning.

There is a refreshing quality to recent neoclassical thinking in that it mostly displaces the question of the body as origin. [...] [We] regard with some cautious degree of approval the appearance of a body in high-neoclassical theory (as, for example in Debreu's Theory of Value or in Arrow and Hahn's General Competitive Analysis) in which bodily functions of consumption, production, distribution, choice and so forth only obliquely relate to a central, unifying dimension (Ruccio and Amariglio 2003, 110).

Is Bourbaki's refreshing liberation from meaning the virtue of a postmodern society that is only "obliquely" unified by the market? Debreu would probably blush to read such lines. He hardly ever even removed his tie! How could he have endorsed such a liberated subject? It was discreetness, not a concern for a pluralist society that made him withdraw from the 'unified body' of classical economics. Debreu's work does not touch any body, neither at its surface, nor at its origin.

\section{Deriving consequences}

The fourth step concerns the kind of consistency the axiomatic method requires. Here we enter the playground of rigor, and nothing but rigor: proceeding step-by-step from 'fully specified' assumptions to conclusions. While the first three steps did not correlate with any intellectual effort, here all the labor and affectivity of mathematical reasoning comes into play. The philosophical question at this step is how formal and mathematical logic relate. Does mathematical logic add something to formal logic, or, the other way around, ${ }^{5}$ is the language of logic proper? This question once moved the generation of Frege, Whitehead and Russell. Debreu and Bourbaki are reluctant to enter such debates.

Whether mathematical thought is logical in its essence is a partly psychological and partly metaphysical question which I am quite incompetent to discuss. [...] It serves little purpose to argue that

\footnotetext{
${ }^{5}$ For a discussion of the axiomatic method in economics regarding the relation of mathematics and logic see Vilks 1992.
} 
logic exists outside mathematics [...] Logical or (what I believe to be the same) mathematical reasoning (Bourbaki 1949, 2).

Debreu also simply identifies rigor with valid reasoning: "The theory of value is treated here with the standards of rigor of the formalist school of mathematics. The effort towards rigor substitutes correct reasoning and results for incorrect ones" (Debreu 1959, 1).

Note again that 'deriving consequences' does not describe the actual practice of axiomatic theorizing, but rather its result. Only when the mathematical proof is presented in its final shape does one 'derive consequences'. While the reading of a proof might have a great aesthetic appeal, its writing is a rather dirty, lengthy, and uncertain process of trial and error. Writing a proof is like groping one's way in the dark, playing with ever-weaker 'assumptions', and trying to struggle through a forest of tautologies. Here I may report an anecdote of one of Debreu's students, Mark Blaug. During a summer course in 1955 at Michigan University, a doubt arose about whether a line in the proof was correct. Instead of thinking this through in class, Debreu left the room. After some time he finally returned with the words "of course, it is correct". The actual mathematical labor, as it were, does not take place in the classroom or any other public place.

Obviously, the term 'consequences' has no causal meaning in logical derivation. To derive consequences is to work through logical implications with the aim of proving the consistency of the axioms. Debreu's existence proof did precisely that: it showed that the mathematical relations ('assumptions') he specified as the axioms did not contradict each other. Debreu's proof was an indirect as opposed to a constructive proof, showing that a disequilibrium leads to a violation of the axioms. ${ }^{6}$ Equilibrium and consistency are thus equated.

For this reason Debreu rejected the study of the stability of equilibrium-one of the most contested issues in economic theory after Debreu. "(W)hen you are out of equilibrium, in economics you cannot assume that every commodity has a unique price because that is already an equilibrium determination" (Debreu, quoted in Weintraub 2002, 146). Debreu believed that the very notion of market disequilibrium is a misnomer since in such a state there could be no conceivable price

\footnotetext{
${ }^{6}$ This is the point where von Neumann's use of the axiomatic method differs from Debreu's Bourbakian use. Von Neumann always stressed the need for a positive constructive analysis. Only then could the intuition of strategic behavior enter economic theory, as it is omitted in GET (see Giocoli 2003).
} 
system whatsoever. Economic models are only worth anything insofar as they can be shown to have a logically consistent solution, that is, as long as they are equilibrium models. And this applies today to the same extent to models of growth, innovation, or uncertainty. And so Debreu said about those who engaged in the

theory of temporary equilibrium, a so-called theory of disequilibrium (a misnomer since it is a theory of equilibrium under new constraints). They show, if it were needed, that the concept of equilibrium is an organizing intellectual concept of great generality with which it is difficult to dispense in the social sciences (Debreu, quoted in Feiwel 1987, 253).

\section{Interpreting}

Debreu mentions interpreting as the fifth and last step of the axiomatization, although the separation of interpretations guides the axiomatization. But, is interpreting a required part of the axiomatization? Or is it rather like a fifth wheel that one does not need, crams into a corner and forgets? Regarding the interpretations themselves, what difference does it make if they are subjected to such separation from the process of axiomatization?

Debreu illustrates the separation of theory and interpretation with a strong image of a theory having blood, flesh, and bones. He talks about an "acid test" that economic theories have to pass in order to be called rigorous-an "acid test of removing all their economic interpretations and letting their mathematical infrastructure stand on its own" (Debreu 1991, 3). Acid is put on the body of theory, corroding all the flesh of meaning and leaving the structural skeleton behind. Our flesh is what makes us sensible beings, responsive to touch, and thus vulnerable to offence. Accordingly, an axiomatized theory might have a strong backbone, yet has nothing to carry, is insensitive to its surrounding, and immune to criticism. And so, Debreu says, "As a formal model of an economy acquires a mathematical life of its own, it becomes the object of an inexorable process in which rigor, generality, and simplicity are relentlessly pursued" (1986, 1265, emphasis added). An axiomatized theory may have a life, but it is a life without affection-like a skeleton haunting economic science since 1959.

Debreu's corrosion of interpretation is in fact radical. By using the terms 'content' and 'interpretation' of theories interchangeably he implies that interpretations are not interpretations of things that are 
independently given without, or before, being interpreted, as most scientists have believed since Bacon. Economic content is nothing but interpretation. This sounds like a hermeneutical claim. Debreu, however, equates content and interpretation not in order to highlight how the theorist is enmeshed in the material he attempts to grasp, but rather to let interpretations appear as things. In light of an axiomatization, interpretations are no longer activities. They are themselves things to be discovered "whenever a novel interpretation of primitive concepts is discovered" (Debreu 1986, 1265). The act of interpreting simply disappears from the stage of rigor. Interpretations lie around in the world waiting to be discovered: the task of economists is then to pick them up and to fill them into structures in order to give those a consistent shape-like a Taylor-designed worker, as Bourbaki did not want to admit about the 'working mathematician'.

One could say that the axiomatic method is nothing but the 'Taylor system' for mathematics. This is however, a very poor analogy; the mathematician does not work like a machine, nor as the workingman on a moving belt; we cannot over-emphasize the fundamental role played in his research by a special intuition* [...]

*Like all intuitions this one also is frequently wrong (Bourbaki 1950, 227).

That little footnote reveals the full ambivalence of the status of theoretical practices in the axiomatic method. Explications are excluded from intellectual practices: in order to be rigorous, one needs to be indifferent to all expressive, descriptive, and explicative practices. ${ }^{7} \mathrm{~A}$ 'rigorous interpretation' or 'rigorous reformulation' is inconceivable. Interpretations are not more or less suited, more or less accurate, but only vague. To be rigorous is to rigorously avoid the question 'what does this mean?' As a consequence, the sources of meaning in the practice of economics are never confronted when doing mathematical economics. This indifference to everything one usually associates with theoretical activity is the core of the axiomatic separation discussed in the preceding pages. Interpretations are not made. They are just there.

Weintraub is moderate when speaking of Debreu's "take-no-prisoner attitude when it came to specifying the 'economic' content of the

Within the textual hierarchy of the axiomatic method one never arrives at interpretations, but as Bourbaki said, at "remarks": "definitions, axioms, theorems, propositions, lemmas, corollaries, remarks" (Bourbaki 1968, v). More cannot be said. 
exercise" $(2002,116)$. But Debreu not only takes no prisoners, as though a commissar of economics, but also indirectly undermines and discourages interpretations. Not only are all interpretations potential economic theories, but all interpretations are also epistemically equivalent. Even if Debreu believed that there is no economics without interpretive efforts, he provided no means for encouraging them to be epistemically relevant. Rather than acting as a democratic, pluralist diplomat, Debreu wiped out the need for evaluating economic theories. But only by means of such evaluations could something of value be at risk for the economist.

\section{THE FOUR VIRTUES OF THE AXIOMATIC METHOD AND THEIR SUPPLEMENT: THE ECONOMIST}

According to this image of the axiomatic method, it must seem like a miracle that Debreu was able to justify the advantages of rigor and the axiomatic method to the economist. There is nothing left of what one would naturally associate with the practice of economic theory. In fact when it comes to selling the advantages of the axiomatic method, Debreu continuously backs away from the separation of mathematical form and economic content just described. Each advantage can only be established by smuggling other intellectual values than axiomatic rigor back into the analysis. There are four advantages Debreu repeatedly refers to: generality, weakness of assumptions, clarity of expression, and freedom from ideology.

\section{Generality}

"The pursuit of generality in a formalized theory is no less imperative than the pursuit of rigor" (Debreu 1986, 1267). How are the rigor and generality of GET related?

GET is usually called general because it is not restricted to a particular market such as the market for apples, oil, kidneys or the market for Gran-Vitara-AWD-metallic-blues. GET is general in that it encompasses all markets, since only children, politicians, moralists, and marketing experts believe that one market is independent from another. In 'the economy' everything depends on everything else. Generality as a virtue in the philosophy of science, moreover, refers to the explanatory scope of theories, and corresponds to the old ideal of explaining much by little. 
Debreu gives us the impression that GET gains generality by an axiomatization in this last sense of explanatory scope-that is, that GET extends the limits of other theories and is applicable to a greater range of phenomena. "A newly discovered interpretation", he claims, "can then increase considerably the range of applicability of the theory without requiring any change in its structure" $(1991,5)$. In the same terms, he even presents the axiomatic method as appropriate to the ontic properties of the market.

A global view of an economy that wants to take into account the large number of its commodities, the equally large number of its prices, the multitude of its agents, and their interactions requires a mathematical model (Debreu 1991, 3).

Perhaps Debreu really believed that the economy is complex. But did this belief actually inform his work?

Debreu tops this assertion of the propriety of mathematics by claiming that mathematics is "neutral" because commodities and prices are numerical things: "Since economics gives a central role to quantities of commodities and prices, the use of mathematics seems entirely neutral" (in Feiwel 1987, 253). But on what grounds does Debreu refer to this quantitative reality of commodities and prices? Are we now to enter a discussion of the ontology of commodities?

[T] here is no firm evidence that prices, commodity units and money were ever constituted as numbers in some pristine ontological sense: they were (and still are) contingent upon a whole range of other social practices, might be reorganized in a myriad of ways, and exhibit no 'natural' or stable mathematical character (Mirowski forthcoming).

Did Debreu, in other words, really believe that commodities could be convex in any sensible way? In what sense is generality achieved by the axiomatic method?

The actual meaning of Debreuvian generality is not that of traditional philosophy of science. The axiomatized GET does not encompass several market theories of particular markets, but is independent of them. How could a theory with a structure that is independent of its (referential) meaning be called general? Debreu relies here on a confusion between generality as the encompassment of content, and formality as the absence of content. Abstraction and 
formalization are two different practices. What Debreu praises as generality is freedom from the logic of the particular and general. By 'generality' he means that one can generate a market theory out of any interpretation of the primitive concepts immediately and effortlessly, or as Bourbaki said, "without forging one's means personally" $(1950,227)$. As Debreu put it in his Nobel lecture: "The axiomatization may also give ready answers to new questions when a novel interpretation of primitive concepts is discovered" (Debreu 1984b, 275). The economist is able to immediately leap over from an interpretation to a fully developed 'theory' without any effort of generalizing. Debreu thus unwittingly admits that his formalism makes theoretical efforts redundant. With the axiomatic method the theorist can be substituted for just like the primitive concepts-effortless economics.

The example Debreu repeatedly refers to in order to illustrate, and celebrate, the virtue of generality, is markets with uncertainty (developed in chapter six of his Theory of value). The difference between certainty and uncertainty makes the world for a group of economists such as the Austrian, institutionalist, evolutionary, and behavioral economists. In these cases, uncertainty challenges economic theorizing since the market cannot be fully determined let alone be listed in advance within a unique 'universe of discourse'. In Debreu, however, whether commodities are certain, in the sense that we know everything about them, or uncertain because of time, is a matter of the interpretation of the primitive concept of 'commodity'. Uncertainty does not affect the axioms themselves. Debreu does acknowledge the importance of the difference between certainty and uncertainty, but cannot incorporate it within the axiomatic scheme: "Several important questions left unanswered are emphasized below [in chapter six]. One may stress the certainty assumption made, at the level of interpretations" (1959, x). On that level, however, nothing really happens since, "by a simple reinterpretation of the concept of commodity", one immediately leads to a theory of uncertainty $(1991,5)$. The problem of uncertainty is solved by moving it outside of theoretical concern. Weintraub assesses the value of such re-interpretations as follows:

Debreu's evident enthusiasm [...] over his capacity to incorporate 'uncertainty' into the axiomatized model by keeping the identical mathematical formalism but redefining the 'interpretation' of the commodity thus should not be regarded as a new contribution to the economic theory of risk or ignorance; rather, in this reading, Debreu 
developed it as a ratification of the structural character of his axioms (Weintraub 2002, 121).

Debreu used uncertainty as a ratification of his method. But was a ratification needed? Could issues of uncertainty have touched Debreu's 'mother structures'? No; the application of uncertainty was rather a way to show that in fact nothing happens if one reinterprets, and that a reinterpretation is actually not needed for GET to stand. Reinterpretations do not make a difference-disillusioning, to say the least, for those who want to attack, or defend, GET on the basis of its supposed economic meaning.

\section{The weakness of assumptions}

Close to the virtue of generality is the weakness of assumptions. Recall that assumptions in Debreu are not weak in relation to a basic belief of the theory-its 'ontology'-as discussed in the philosophy of science. In Debreu, the weakness of assumptions is expressed in terms of the Bourbakian hierarchy of mathematical structures, the weakest of all assumptions being $x \in X$. To say that the assumption of transitivity is weaker than that of continuity is to say that transitivity is mathematically implied by continuity but not vice versa. In terms of cognitive capacities, for example, it could be the other way around.

Though clearly a matter of mathematical structures, Debreu gives his audience the impression that these structures are related to the domain of applicability: "The mathematician's compulsive search for ever weaker assumptions is reinforced by the economist's awareness of the limitations of his postulates", as he describes the interaction of mathematicians and economists $(1986,267)$. But what is the effect on the 'domain of applicability' if the mathematician "expurgated superfluous differentiability assumptions from economic theory" (1986, 267)?

The issue in the background here is what came to be known as economics imperialism: the infusion of economic ideas into other social sciences and economic talk in general. Economics imperialism is problematic and different from a fruitful interdisciplinary effort because economists lose their sense of an economic domain and enter other domains without caring about their characteristics, that is, without sensing resistance when passing borders. Ironically, on the 
grounds of the confusion of assumptions and axioms Debreu could argue that the axiomatic method limited economics imperialism. ${ }^{8}$

The exact formulation of assumptions and of conclusions turned out, moreover, to be an effective guide against the ever-present temptation to apply an economic theory beyond its domain of validity (Debreu 1986, 1266).

Do we sense the irony in these lines? Debreu turned perhaps the greatest vice of post-war economics into a virtue of his method-to restrict it. How could he possibly believe that his axiomatized GET ever functioned as such a regulative device to maintain closeness to a particular domain of economic life?

Gary Becker could be said to have received the Bank of Sweden Prize for showing that Debreu not only proved that the logic of the market is independent of its interpretation, but that market theory is not even restricted to the phenomenon of markets. In this respect, Becker goes further than Debreu, since he uses the lack of interpretation of the market as a vehicle to turn market theory into a method. Without Debreu, however, this step would have been impossible. Mirowski puts the link between the axiomatic method and economics imperialism in the following words:

The practical effect of the Cowles program was to "toughen" up the mathematical training of economists and thus repel anyone trying to trespass from another social science [...] What Cowles ultimately sought to do was to shore up the boundaries between neoclassical economics and the other social sciences; pending that, transcendental urge was re-conceptualized as the periodic forays of the economic imperialists, bringing back home raw materials wrest forcibly from the natives as fuel for their stationary engine of analysis (Mirowski 2001, 266-267).

Contrary to his own assertion, most economists would certainly see Debreu's influence in their attempts to regain a sense of the economic home domain-notably by relaxing the rather strong assumptions that

\footnotetext{
${ }^{8}$ Debreu shares here the same hope as Koopmans who, already in 1957, had written about the 'sobering effect' of rigor: "The best safeguard against overestimation of the range of applicability of economic propositions is a careful spelling out of the premises on which they rest. Precision and rigor in the statement of premises and proofs can be expected to have a sobering effect on our beliefs about the reach of the propositions we have developed" (Koopmans 1957, 147). Sobering yes, but a 'safeguard against overestimation'?
} 
came to be assigned to Debreu's model, such as perfect knowledge, perfect rationality, symmetric information, etc. Ironically, Debreu could present these attempts at escaping the narrowness of his GET as evidence for his method serving as a benchmark.

Its role as a benchmark was also perceived clearly, a role which prompted extensions to incomplete markets for contingent commodities, externalities, indivisibilities, increasing returns, public goods, temporary equilibrium (Debreu 1986, 1268, emphases added).

The economists' sensibility for an economic domain, which they try to regain when they engage in such theorizing, could still be read by Debreu as an "extension" of his axiomatic GET-a quasi-application. Since the weakness of assumptions is measured not in ontic but in mathematical terms, relaxing the supposed economic assumptions of GET does not change the mode of theorizing. Therefore, even if market theories start with an intuition about the (ontic) domain of the market they can turn out analytically equivalent to Debreu's GET. For this reason even the alternatives to GET reinforce its underlying standards of rigor, as is most apparent in the case of behavioral economics. The more economists struggle to be 'realistic', the more they 'extend' Debreu's structure. Debreu thus brought a negative closure to economics.

\section{Clarity of expression}

Perhaps the most salient excuse for mathematical economics after 1945 was Samuelson's catchphrase that mathematics is a language, with which one says the same thing, just more clearly (Samuelson [1947] 1961). Debreu also promoted this belief:

Still another consequence of the axiomatization of economic theory has been a greater clarity of expression, one of the most significant gains that it has achieved. To that effect, axiomatization does more than making assumptions and conclusions explicit and exposing the deductions linking them. The very definition of an economic concept is usually marred by a substantial margin of ambiguity. An axiomatized theory substitutes for that ambiguous concept a mathematical object that is subjected to definite rules of reasoning. Thus an axiomatic theorist succeeds in communicating the meaning he intends to give a primitive concept because of the completely specified formal context in which he operates (Debreu 1986, 1266, emphases added). 
Whence, out of the blue, this expressiveness? How can one communicate an intended meaning with a language that is separated from any meaning? That is a sheer impossibility as long as primitive concepts are not conceptualized, but substituted for with a mathematical object. The only thing clear in Debreu is the separation of structure and meaning so that meaning is identified with ambiguity. Debreu of course knew that axioms are not expressive. He even made the separation of mathematical form and economic content typographically visible in his Theory of value. "In order to bring out fully this disconnectedness [of theory from its interpretations], all the hypotheses, and the main results of the theory, in the strict sense, are distinguished by italics" (1959, x). Only in the "(s)mall type passages", which are "irrelevant for the logical developments of the text proper", is it "permissible to draw upon an intuitive knowledge of the physical world" (Debreu 1959, 2). ${ }^{9}$ Bourbaki preferred asterisks to mark these passages, the "omission" of which "of course, have no disadvantage, from a purely logical point of view" (Bourbaki 1968, v). The point is, however, that Debreu in this way not only substitutes the "substantial margin of ambiguity", but renders meaning altogether inexpressible.

Nevertheless, Debreu was very successful in making the economist believe that his axiomatization implies "clarity of expression". The margins of economic theories are still narratives today, while the analytical core consists of formal modeling. Intellectual efforts in economics do not take place in literary passages. But did this enhance communication among economists? To some extent, yes. The more mathematics, the less need for literary skills, and the easier to communicate beyond the cultural noise of ordinary languages. On the other hand, what is the Bourbakian Esperanto of $x \in X$ good for if it is free from expressiveness? What is the clarity of language good for if disagreements, for example, become impossible? Heilbroner and Milberg argued that one symptom of the 'crisis of vision' is that the economic "discipline appears to be less and less [...] a matter of general agreement" (1995, 15). If everything one can say scientifically in economics has already been said implicitly, how reluctant must an

\footnotetext{
${ }^{9}$ Note the subtlety: like a Bourbakian slip, Debreu notoriously speaks of the "physical world" when it comes to referential meaning, as though he never even considered that economic theory refers to the economic world.
} 
economist be to listen to someone else? The drawback of the clarity of expression is a reluctance to engage in debates. ${ }^{10}$

\section{Free from Ideology}

The last advantage is the most subtle to interpret, namely that "economic analysis was sometimes brought closer to its ideologyfree ideal" (Debreu 1986, 1266). Debreu illustrates this with the interpretation of the two welfare-theorems:

Foes of state intervention read in those two theorems a mathematical demonstration of the unqualified superiority of market economies, while advocates of state intervention welcome the same theorems because the explicitness of their assumptions emphasizes discrepancies between the theoretic model and the economies that they observe (Debreu 1986, 1266).

Up until the formalist revolution the political meaning of the welfare implications of GET had been debated in such terms, most prominently in the socialist calculation debate. Since then, by and large, the discussion has calmed. But has the issue been resolved? Is economics free from ideological issues because it has resolved them scientifically? Did it establish an epistemic authority that all political parties agree on? Have economists ever been taken seriously as political judges? Certainly not Debreu, although in his philosophical naivety he, too, evinced the dream of rigorous blackboard politics:

The theory that we are discussing tries to be ideologically neutral. It deals with problems that are basic and common to all economic systems, for instance the efficient allocation of resources through decentralized procedures [...] Mathematical models of the economy help to analyse the optimal extent of this decentralization. The risk

\footnotetext{
${ }^{10}$ Note the difference to the following argument that rigor constrains the range of discussable problems: "The desire to derive arguments rigorously means that they [economists] are confining themselves to saying what these theoretical tools allow them to say. Given the state of the techniques available to economists, pursuing this form of rigor has severely constrained what economists have been able to say" (Backhouse 2005, 383). Backhouse does grant the theoretical tools of rigor expressiveness in some limited domain (we know the song: allocation instead of distribution, competition instead of industries, and so on). It is again by virtue of the secondary narratives that have been assigned to these tools that this is so. The actual problem, however, was not that rigor constrained the range of problems, but that it made the economist forget the economic problems since one never faces them while theorizing.
} 
of misinterpretation [...] is lessened by the uncompromising exactness of the modelization (Debreu, in Feiwel 1987, 246).

The ideologically neutral 'decentralization of the allocation of resources'? What then is the "optimal extent of this decentralization"? 65\%? And is the optimization function 'smooth'? In a late interview Debreu's actual attitude-aloof from political debate rather than concerned to resolve it-is most apparent:

[C]onsider for example the Pareto optimum of a general equilibrium. It gave rise to conceptual discussions between the liberal economists who said: "Ah! Voila, this is the proof!" and other, rather Marxist oriented economists who said: "Ah! Voila! The assumptions that one has to make for a Pareto optimum are never met!" I simply took the following stance: You can derive whatever conclusions you want from the assumptions. If it satisfies liberal economists and Marxists, too: Perfect! There is nothing better I could ask for. Intellectually you are carried by the current of ideas, and you simply end up where this current will take you (Debreu, quoted in Bini and Bruni 1998, my translation from the original French).

Marxian? Liberal? Both? Parfait! Economists can argue in favor of or against capitalism 'by simply reinterpreting the primitive concepts'. $Q E D$, economics is a science!

The confusion Debreu's claim relies on is clear. Debreu did not solve a political problem by any epistemic means. He rather de-politicized economics. What Debreu celebrates as the liberation from ideology is freedom from political relevance. Only in this sense is economics a science, and not in accordance with any standard of the philosophy of science, as I have been arguing. Economics is systematic, yes, but not systematic knowledge. Debreu proved rigorously that the authority of rigor supports no political interpretation of GET. What Debreu hurrahs-that economics is not (politically) biased-others, at the same time, began to hoot at-the fact that economics is (politically) irrelevant. Debreu's work marks the turn in economics from the suspicion of ideology into the lament of insignificance.

But what then about the 'the risk of (political) misinterpretation' Debreu mentioned? Was Debreu's discreet intervention really so sobering that it disillusioned all associations of GET with political meaning? At least one economist of the neo-Walrasian community, Frank Hahn, thought so and sought to use the formalist void of GET for a critical purpose: 
[T]his negative role of Arrow-Debreu equilibrium I consider almost to be sufficient justification for it, since practical men and ill trained theorists everywhere in the world do not understand what they are claiming to be the case when they claim a beneficent and coherent role for the invisible hand (Hahn 1974, 52).

According to Hahn, GET proves rigorously, precisely in its axiomatized form, what one cannot argue with it. ${ }^{11}$ GET is critical about political misunderstandings. But the political misunderstanding of what? Of GET itself! With Debreu, GET clears up the misunderstandings that happened during its own tradition, and thus to a great extent the misunderstanding of this very tradition, namely that there is an actual political claim to be made about the invisible hand. Debreu proved, in other words, that if GET ever was bestowed with meaning, this meaning did not stem from an epistemic concern, but from ideological motives. Taking Hahn's stance seriously, Debreu showed that GET as an economic theory could only be ideological!

So, was Debreu successful in the sense Hahn envisioned? Are all misunderstandings cleared up? It is true that the association of mathematical rigor with the full determinability of the economy, and thus scientific socialism, is outmoded. This happened, to say the least, no less because of McCarthy's violent politics than Debreu's sobering Bourbakism. But how about the other misunderstanding, that economists associate the intellectual elevation of economic theory with liberal virtues? Is it not the riddle of post-war economics that despite its internal complaint of being politically irrelevant, economics came to be associated with a neoliberal advocacy of the market? In the preceding pages I noted such ideological 'infestation' of formalism in economics at several points. What then is the logic of Debreu's 'axiomatic liberalism'?

Some, particularly Marxists, such as James Cypher, did charge Debreu directly with intentionally supporting neoliberal policies:

Most of the orthodox modelling of the effects of NAFTA has been based on either some or all of the assumptions relevant in the construction of a proof of the existence of general equilibrium under perfectly competitive (Walrasian) conditions. [...] In the briefest from, this construct assumes that all markets clear (therefore, by

\footnotetext{
${ }^{11}$ Blaug called Hahn's move a "ju-jitsu” defense of GET (2003, 152). Although Blaug agrees that "the best way not to learn how markets function [...] is to study general equilibrium theory" $(2003,154)$, he did not appreciate that this negative role can actually be critical.
} 
assumption there is no unemployment), all products are divisible, there are rational maximizers of independent utility functions, all firms face competitive factor and product markets, all participants are endowed with perfect knowledge (costly attained), banking and finance operate seamlessly thanks to perfect knowledge of the future (Cypher 1993, 153).

"Assuming the mantle of scientific objectivity", economists "introduce only those assumptions which enable modellers to 'prove' that Free Trade Agreements are mutually beneficial (Cypher 1993, 146)." But since all the assumptions are either wrong or at least distortions NAFTA is ill-founded. The Marxists Resnick and Wolff argued on the same grounds that "in the award to Professor Debreu, the Nobel committee made a choice between the two traditions [class and nonclass theories]" $(1984,30)$. The assumptions of neoclassical GET exclude the consideration of class. Yet after the preceding discussion it should be clear that Debreu never spoke about any of these 'assumptions', nor gave any public sign of considering them. The alliance between formal economics and neoliberal politics, therefore, is not a matter of ontological suppositions.

The same applies to a more modest way of linking Debreuvian rigor and neoliberalism, as attempted by Roger Backhouse.

The conventional view is that the use of mathematics protects economists from ideology, as well as from being accused of being driven by ideology. However, there is another case that can be made. This is that the intellectual value judgments that underlie technical economics, as it currently exists, bias one toward conservative conclusions. [...] Individual optimisation and perfect competition have been, for the most part, adopted not because economists believe them to be correct but because they permit rigorous analysis (Backhouse 2005, 382n, emphasis added).

Is rigor biased towards neoliberalism? Why? Because, according to Backhouse, theories easily utilizable for neoliberal politics are by chance just the same as those that are easily amenable to the intellectual value of rigor. Other values and other techniques (e.g., simulation as opposed to axiomatics) could be biased in another political direction. Are economists neoliberals merely by virtue of analytic convenience? Are they irresponsible enough to pay the costs of supporting this or that politics merely for the sake of maintaining rigor? No! At least, this charge cannot be directed at Debreu. Backhouse does not consider that 
the same intellectual virtue of rigor can also evoke beliefs in the ontological transparency and determinability of the economy, and indeed has been biased for most of the 20th century towards socialism. Rigor does not support a particular political ideology for methodological reasons.

The logic of axiomatic liberalism, as suggested in the previous pages, is rather that of a contingent association: scientific aloofness and discreetness - the distance one takes from politics-plays out in politics as a particular political program for freedom. Only there, on an associative level, can one link the separation of content and form with the separation of politics and markets. The feeling of formal aloofness nourishes neoliberal imaginaries of the harmless self-policing of markets. In Mirowski's words:

A mathematized world-say, a mathematized economy-by extension then also seems capable of policing itself, since it is being portrayed as existing independently of the way any analyst might characterize it, puttering along on its own terms (Mirowski forthcoming).

The obvious question is how this "by extension" takes place. One thing became clear in the preceding discussion: Debreu cannot be blamed. His Bourbakism does not justify an alliance between scientific monism and neoliberal hegemony. By not making any economic claims Debreu did not claim a truncated version of liberalism. He separated mathematical form and economic content as a way to avoid that association. Blame should be laid on others-those, who outside the production centers of mathematical economics are nevertheless able to utilize it as the epistemic authority for this or that political interest. Identifying these others is not the present task.

Important for the role of the axiomatic method is rather whether the Debreuvian economist can possibly take responsibility for such utilizations. Does the axiomatic method allow economists to reflect on, and possibly prevent, the ideological use of their work? As long as the self-understanding of economists is to be prior, beyond, aloof, or otherwise separated from the political meaning of their work, the political use of their authority will always work against them. And this is the irony of Debreu's assertion that he freed economics from ideology: precisely because Debreu felt himself to be free from it, others could freely find some murky ways to mobilize the aloofness of rigor as a 
symbol of the superiority of markets. The problem of 'Debreuvian economics' is that economists do not feel responsible for the many uses of economics in messy political and social discourse. And this applies as much today, after GET and Bourbakian rigor, as it did half a century ago.

After 1983 Debreu himself was confronted with such misunderstandings which his work, as opposed to Hahn's hope, could not clear up. After he celebrated the beneficial consequences of the invisible hand of formalism at the Nobel festivities he must have felt its rather painful consequences. The suspicion of ideology (that makes Gerard Debreu a tragic character) was not stilled, but to the contrary, was reinforced by the appearance of being free from it. After all, are cultures of suspicion not reinforced by the presence of those who declare they are beyond them? After Debreu had avoided political questions for his entire life, following 1983 they fell upon him with the unbearable weight of the Nobel ethos: 'Mister Debreu', he was asked by the entire world, 'What does that mean?' What does it mean that you have proven that "the market works automatically" (as the Nobel committee announced in its press release)? Should we position more or less rockets toward the East? Debreu was addressed as an authority of meaning, not of structures. For nobody in economic talk was ever interested in structures! It was because of such questions that Debreu became explicit about his methodology after 1983. And it was for this reason that he insisted on the strict separation of mathematical form and economic content, excusing himself with a voice of guilt: 'Sorry, I did not mean that'.

\section{REFERENCES}

Amariglio, Jack, and David Ruccio. 2003. Postmodern moments in modern economics. Princeton: Princeton University Press.

Anderson, Robert. 2005. Gerard Debreu. The Econ Exchange: News and Notes from the Department of Economics University of California, Berkeley, 8 (1): 6-10.

Arrow, Kenneth, and Gerard Debreu. 1954. Existence of an equilibrium for a competitive economy. Econometrica, 22 (3): 265-290.

Backhouse, Roger. 2005. The rise of free-market economics: economics and the role of the state since 1970. History of Political Economy, 37 (Supplement 1): 355-392.

Bini, Piero, and Luigino Bruni. 1998. Intervista a Gerard Debreu. Storia del Pensiero Economico, 35: 3-29.

Blaug, Mark. 2003. The formalist revolution of the 1950s. Journal of the History of Economic Thought, 25 (2): 145-156.

Bourbaki, Nicolas. 1949. Foundations of mathematics for the working mathematician. The Journal of Symbolic Logic, 14 (1): 1-8. 
Bourbaki, Nicolas. 1950. The architecture of mathematics. The American Mathematical Monthly, 57 (4): 221-232.

Bourbaki, Nicolas. 1968 [1939]. Elements of mathematics: theory of sets. Reading (MA): Addison-Wesley.

Clower, Robert W. 1995. Axiomatics in economics. Southern Economic Journal, 62 (2): 307-319.

Corry, Leo. 1992. Nicolas Bourbaki and the concept of mathematical structure. Synthese, 92: 315-348.

Corry, Leo. 1997. The origins of eternal truth in modern mathematics: Hilbert to Bourbaki and beyond. Science in Context, 10 (2): 253-97.

Cypher, James M. 1993. The ideology of economic science in the selling of NAFTA: the political economy of elite decision-making. Review of Radical Political Economics, 25 (4): 146-164.

Debreu, Gerard. 1959. Theory of value: an axiomatic analysis of economic equilibrium. New Haven, London: Yale University Press.

Debreu, Gerard. 1984a. Banquet speech. In Les Prix Nobel, ed. Wilhelm Odelberg. Stockholm: Nobel Foundation.

Debreu, Gerard. 1984b. Economic theory in the mathematical mode. The American Economic Review, 74 (3): 267-278.

Debreu, Gerard. 1986. Theoretic models: mathematical form and economic content. Econometrica, 54 (6): 1259-1270.

Debreu, Gerard. 1991. The mathematization of economic theory. The American Economic Review, 81 (1): 1-7.

Dierker, Egbert. 1974. Topological methods in Walrasian economics. Berlin: Springer.

Feiwel, George. 1987. Oral history II: an interview with Gerard Debreu. In Arrow and the ascent of modern economic theory, ed. George Feiwel. London: Macmillan, 243257.

Giocoli, Nicola. 2003. Fixing the point: the contribution of early game theory to the tool-box of modern economics. Journal of Economic Methodology, 10 (1): 1-39.

Hahn, Frank. 1974. On the notion of equilibrium in economics. London: Cambridge University Press.

Hands, D. Wade. 1985. The structuralist view of economic theories: a review essay, the case of general equilibrium in particular. Economics and Philosophy, 1: 303-335.

Heilbroner, Robert L., and William S. Milberg. 1995. The crisis of vision in modern economic thought. New York: Cambridge University Press.

Ingrao, Bruna, and Giorgio Israel. 1990. The invisible hand: economic equilibrium in the history of science. Cambridge, MA: MIT Press.

Jorland, Gerard. 2000. The coming into being and passing away of value theories in economics (1776-1976). In Biographies of scientific objects, ed. Lorraine Daston. Chicago: University of Chicago Press.

Khan, M. Ali. 1993. The irony in/of economic theory. MLN, 108 (4), 759-803.

Kirman, Alan. 1989. The intrinsic limits of modern economic theory: the emperor has no clothes. The Economic Journal, 99: 126-39.

Koopmans, Tjalling. 1957. Three Essays on the state of economic science. New York: McGraw-Hill.

Mas-Colell, Andreu. 1974. An equilibrium existence theorem without complete or transitive preferences. Journal of Mathematical Economics, 1 (3): 237-246. 
Mirowski, Philip. 2001. Machine dreams: economics becomes a cyborg science. Cambridge: Cambridge University Press.

Mirowski, Philip. Forthcoming. The unreasonable efficacy of mathematics in economics. In Elsevier Handbook of the Philosophy of Science, 13: Philosophy of Economics, ed. Dov M. Gabbay, et al. Amsterdam: Elsevier.

Mirowski, Philip, and E. Roy Weintraub. 1994. The pure and the applied: Bourbakism comes to mathematical economics. Science in Context, 7 (2): 245-272.

Ramrattan, Lall, and Michael Szenberg. 2005. Gerard Debreu: the general equilibrium model (1921-2005) in memoriam. American Economist, 49 (1): 3-13.

Resnick, Stephen A., and Richard D. Wolff. 1984. The 1983 Nobel Prize in economics: neoclassical economics and Marxism, Monthly Review, December: 29-46.

Samuelson, Paul. 1961 [1947]. Foundations of economic analysis. Cambridge (MA): Harvard University Press.

Schmeidler, David. 1969. Competitive equilibria in markets with a continuum of traders and incomplete preferences. Econometrica, 37 (4): 578-85.

Sen, Amartya. 1973. Behaviour and the concept of preference. Economica, 40 (159): 241-259.

Varian, Hal. 1984. Gerard Debreu's contribution to economics. Scandinavian Journal of Economics, 86 (1): 4-14.

Vilks, Arnis. 1992. A set of axioms for neoclassical economics and the methodological status of the equilibrium concept. Economics and Philosophy, 8: 51-82.

Walker, Donald A. (ed.). 1983. William Jaffe's essays on Walras. Cambridge and New York: Cambridge University Press.

Walker, Donald A. 2006. Walrasian Economics. Cambridge and New York: Cambridge University Press.

Weintraub, E. Roy. 2002. How economics became a mathematical science. Durham and London: Duke University Press.

Till Düppe is a teaching and research fellow in the department for the history of economics at the University of Hamburg. His main research interest is the historical epistemology of economics, inspired by phenomenological philosophy. This article stems from his doctoral research on The phenomenology of economics: life-world, formalism, and the invisible hand, a summary of which can be found on pp. 132-135 of this issue of EJPE or at <http://ejpe.org/pdf/3-1-ts-5.pdf >. Contact e-mail: <Till.Dueppe@wiso.uni-hamburg.de> 